\title{
CURRENCY BOARDS AND CURRENCY CRISES
}

\section{Gregor Irwin, University College and Department of Economics, University of Oxford}

\begin{abstract}
This paper demonstrates how a currency board can become vulnerable to a crises in which the policymaker is forced to devalue. The model is built from two blocks: first, incomplete information about the devaluation cost faced by the policymaker; and second, unemployment persistence. Incomplete information can result in multiple equilibria. In one class of equilibrium the policymaker has a credibility problem and maintaining the currency board is costly in terms of unemployment. If unemployment is persistent then pressure to devalue can build up over time until it becomes unbearable and the policymaker is forced to devalue.
\end{abstract}

January 2001

Keywords: currency boards, crises.

JEL Classification: F33, F41.

\section{Acknowledgements}

I am grateful to David Vines for his helpful comments and suggestions. 


\section{Introduction}

The experience of the 1990s has led many economists to call into doubt the feasibility of operating pegged exchange rate systems in developed and emerging markets (see Eichengreen et al, 1999, and Mussa et al, 2000). A succession of crises - in Europe, Latin America, and East Asia - have shown that, in a world of highly mobile capital, such systems are prone to destabilising and costly speculative attack. The very fact that a currency peg is adjustable can create an expectation of adjustment that is self-fulfilling (see Obstfeld, 1997a). But by its nature the timing of such a crisis is both unpredictable and uncontrollable, and as a result the welfare consequences can be severe. This has led to the development of the 'two-corner solution' approach to exchange rate policy, which holds that policymakers should choose between the extremes of either a floating exchange rate, or a firm commitment to fix the exchange rate in the form of a currency board (see, for example, International Financial Institution Advisory Commission, 2000, Edwards, 2000, and De Gregorio et al, 1999; for contrary views in support of the middle ground see Williamson, 2000, and Frankel, 1999). The logic of this two-corner solution is that if a currency crisis is to be avoided then either an exchange rate peg should be avoided altogether - in which case the currency should be floated - or policymakers should be 'locked-in' to a fixed exchange rate by a currency board system that prohibits devaluation.

This paper calls into question one element of this two-corner solution: this is the proposition that a currency board provides a durable basis for a fully binding - and therefore credible - commitment to fix the exchange rate. This proposition is undermined using a formal model, which demonstrates how a currency board system can become vulnerable to a currency crises in which the policymaker is forced to devalue. The model does not simply demonstrate that if the cost of maintaining an exchange rate peg is high enough, a currency board will be abandoned; the analysis shows how this can come about. And the explanation is not one based on bad luck - indeed stochastic shocks are deliberately omitted from the model to avoid this complication, even though shocks could potentially compound the policymaker's problem.

The model is built from two essential blocks: first, incomplete information about the political cost faced by the policymaker if the currency board collapses; and second, the persistence of unemployment. The political cost of devaluation is the underlying source of credibility for an exchange rate commitment. It is this cost which provides the policymaker with the necessary incentive to refrain from devaluation. The key factor which differentiates a 
currency board from other types of exchange rate peg - at least so far as the sustainability of the regime is concerned - is that this cost will tend to be higher. But incomplete information about this cost can result in a credibility problem. If the uninformed party (the 'public') believe there is a possibility that this cost is low, they attach a positive probability to a devaluation occurring. If the policymaker faces a high cost of devaluation, he will maintain the currency board, but at the expense of higher unemployment. If unemployment is persistent, then the credibility problem is compounded, and the pressure to devalue and abandon the currency board can build up over time until it becomes unbearable. Ultimately, even a policymaker who faces a very high cost of devaluation, can be forced to devalue.

The paper is set out as follows. The next subsection explains in more detail two of the assumptions which are central to the analysis. The first is the assumption that the policymaker faces a political cost if he devalues and that this will tend to be higher under a currency board system than under other forms of exchange rate peg. The second is the assumption that the public have incomplete information about this cost.

Section 2 sets out the key features of the model and explains the nature of the problem faced by the policymaker.

Section 3 considers the implications of incomplete information in a static context. It is shown how multiple equilibria can exist in which the policymaker maintains the currency board and does not devalue. A distinction is made between full-credibility equilibria, in which no devaluation is expected, and partial-credibility equilibria, in which the public attach a positive probability to a devaluation occurring. In the latter case, if the policymaker fixes the exchange rate, unemployment rises.

Section 4 considers the dynamic implications of the model. A partial-credibility equilibrium has two effects, with opposing implications, on the outcome in subsequent periods. On the one hand, because unemployment is persistent, it will remain high, and this will tend to reduce the credibility of the exchange rate peg. But on the other, because the public learn about the true devaluation cost by observing actual exchange rate behaviour, this may serve to improve the credibility of the peg. It is shown how, under certain conditions, the first effect dominates, and so the fundamentals can deteriorate over time. Moreover, they may do so to such an extent that the policymaker is eventually forced to devalue, even if he faces a very high devaluation cost.

Section 5 presents some conclusions. 


\subsection{Currency Boards, Devaluation Cost, and Incomplete Information}

The purpose of this subsection is to explain the basis for two assumptions which are of fundamental importance to the model presented in the rest of the paper.

The first assumption concerns what it is that makes a currency board distinctive from other forms of exchange rate peg. In operational terms a currency boards can be characterised by the requirement that the entire monetary base is backed by holdings of the reserve currency. The monetary authority acts mechanically to exchange the domestic currency for the reserve currency on demand and at a fixed rate. In a pure currency board system the monetary authority does not hold domestic assets and so is unable to sterilise its foreign exchange dealings. The monetary authority has no discretion in the conduct of monetary policy; this is dictated by market forces and the actions of the authority that issues the reserve currency.

These rules which govern the conduct of a currency board are tightly-specified and strict. And they are typically given weight by legislation, or in some cases by constitutional amendment. However, the essential point is this: legislation can be repealed and constitutions can be re-amended. Currency boards are revocable. The power to do so may not lie with the monetary authority: rather, it may rest with the government, the legislature, or some combination of the two. But this simply means that the monetary authority is not the effective policymaker under a currency board system; it does not mean that the policy options faced by whichever body is the effective policymaker are fundamentally altered. These remain either to fix the exchange rate, or to devalue.

What is more likely to change is the cost faced by the policymaker if a devaluation does occur. It is one thing to suspend currency market intervention and to allow the exchange rate to float; it is quite another to have to push through emergency legislation to make such an action legal in the first place. The cost to the policymaker in the latter case must surely be higher. 2 Ih this paper it is assumed that the key factor that distinguishes a currency board from other types of exchange rate peg is that the policymaker faces a higher political cost of devaluation. And it is the fact that the cost of devaluation is higher that lends credibility to currency boards in the first place. According to the IMF staff's World Economic Outlook in 1997 (p. 84), 'The credibility of CBAs [currency board arrangements] ... comes from the fact

\footnotetext{
1 For more detail on the workings of currency boards see Baliño et al (1997) and Enoch and Gulde (1997)
} 
that a CBA entails a much higher cost of abandoning a fixed parity than is the case for fixedbut adjustable exchange rate arrangements. In most existing CBAs, the exchange rate is set by law, making changes to the exchange rate very costly for governments.' According to Ghosh et al (2000), '... the credibility benefits will only be reaped if the costs of exiting the currency board are sufficiently high. This is why the institutional set up of the currency board is no mere detail: codifying the regime in law (and a fortiori in the constitution) raises the cost of exiting the regime, thereby raising its credibility' (p. 279).

The second assumption to be discussed in this subsection, which is related to the first, is that there is incomplete information about this cost of devaluation. It would be too simplistic to argue that this is the result of the policymaker having privileged access to information not available to other interested agents (the public), for example, concerning the process by which the revocation of a currency board system might be expedited. This would suggest that the problem of incomplete information could be overcome by making the information more widely available. Rather, the argument of this paper is that incomplete information is an inherent problem given the intangible nature of the political cost of devaluation. Because this cost is intangible its magnitude cannot be both observable and verifiable by the public. But even if this were possible there is an additional problem. It is not the absolute magnitude of the cost itself that matters, rather it is the size of the cost relative to the other elements of the policymaker's objective function that is important, and these other elements are also likely to be unobservable and non-verifiable by the public.

A further concern, which we do not develop in the model, but which at least underlines the importance of this model, is that it is probable that the size of the devaluation cost, and the extent of the incomplete information surrounding it, will change over time. A currency board system commits not just the current policymaker, but future policymakers as well. But this, in itself, necessarily means that the size of the devaluation penalty, and the extent of incomplete information, will change over time. For example, the Argentinean currency board was introduced in April 1991 by the President, Carlo Menem, the Minister of Economics, Cavallo Domingo, and the President of the Central Bank, Roqué Fernandez. Ten years later, the holders of all three offices are different. And the composition of the Senate

\footnotetext{
2 Collins (1996) discusses why a devaluation might be politically costly under a fixed exchange rate regime.

3 Rivera Batiz and Sy (2000) take a different approach to modelling the credibility of currency board systems. They assume that the legislative hurdles that must be overcome before a currency board can be abandoned effectively mean a one period delay before a devaluation can occur. However, we believe that the cost of maintaining a currency board, after the intention to dismantle it has been signalled by the policymaker, would ensure that the necessarily legislative approval would be granted rapidly.
} 
and House of Deputies, who passed the legislation which constituted the currency board system, has also changed. As the policymakers have changed in Argentina, it is inevitable that the cost borne by the policymakers in the event of a devaluation will also have changed, and with it the extent and nature of any incomplete information about this cost. (The political changes in Hong Kong, since the inception of its currency board in 1983, have, of course, been even more dramatic).

\section{The Model}

The model outlined in this section is based on Obstfeld (1997b), which in turn has its roots in the model of Barro and Gordon (1983). Because this earlier model is well understood the discussion of this section is deliberately concise. To the Obstfeld model we add a persistence term in the unemployment equation and incomplete information about the cost of devaluation. For simplification, and to sharpen the focus of the analysis, stochastic shocks to employment have been omitted.

Each period the policymaker minimises the following one-period loss function: ${ }^{\square}$

$$
L_{t}=\left(u r_{t}\right)^{2}+\theta\left(\Delta e_{t}\right)^{2}
$$

where $u r_{t}$ is the deviation of unemployment from the target rate of the policymaker and $\Delta e_{t}$ is the rate of devaluation (all variables are in logs). The deviation of unemployment from the target rate is given by:

$$
u r_{t}=\alpha^{1 / 2}\left[-\left(\Delta e_{t}-E \Delta e_{t}\right)+k+\delta u r_{t-1}\right]
$$

where $k$ causes unemployment to be above the target rate (because of some underlying distortion in the labour market) and $\delta$ is a measure of the persistence of unemployment deviations. $E \Delta e_{t}$ is the rate of devaluation expected by the public. It follows from (2) that the policymaker can reduce unemployment through an unexpectedly large devaluation. In the absence of a fixed exchange rate commitment the policymaker sets $\Delta e_{t}$ to minimise (1) subject to (2). The first order condition implies:

\footnotetext{
$4 \quad$ This assumption, which is consistent with Masson (1995), means the policymaker does not take account of the effect his current actions have on future unemployment and on expectations in subsequent periods. Masson (1995) is discussed in more detail below.

Layard, Nickell, and Jackman (1991) provide evidence to suggest there is a high degree of unemployment persistence in developed countries.

6 Implicitly, exchange rate expectations impact on the nominal wage demands of the public. An unexpectedly high rate of devaluation reduces the real wage, increases labour demand, and therefore reduces unemployment.
} 


$$
\begin{aligned}
& \Delta e_{t}=\alpha(\alpha+\theta)^{-1}\left(E \Delta e_{t}+k+\delta u r_{t-1}\right) \\
& L_{t}^{D}=\alpha \theta(\alpha+\theta)^{-1}\left(E \Delta e_{t}+k+\delta u r_{t-1}\right)^{2}
\end{aligned}
$$

where $L_{t}^{D}$ is the loss from the discretionary devaluation policy. Assuming rational expectations:

$$
\begin{aligned}
& E \Delta e_{t}=\Delta e_{t}=\alpha \theta^{-1}\left(k+\delta u r_{t-1}\right) \\
& L_{t}^{D}=\alpha \theta^{-1}(\alpha+\theta)\left(k+\delta u r_{t-1}\right)^{2}
\end{aligned}
$$

Alternatively, if the policymaker fixes the exchange rate the loss, $L_{t}^{F}$, is given by:

$$
L_{t}^{F}=\alpha\left(E \Delta e_{t}+k+\delta u r_{t-1}\right)^{2}
$$

If this policy is fully credible $E \Delta e_{t}=0$ and the loss becomes:

$$
L_{t}^{F}=\alpha\left(k+\delta u r_{t-1}\right)^{2}
$$

As (6) is strictly greater than (8) the policymaker has an incentive to undertake a fixed exchange rate commitment if it will be fully credible. But how can this credibility be achieved? The problem is that the fixed exchange rate policy is time-inconsistent: the policymaker has an incentive to renege and devalue once devaluation expectations have been formed. This can be seen by a comparison of (7) and (4), which shows that, for a given devaluation expectation, the loss from fixing always exceeds that from devaluation:

$$
L_{t}^{F}-L_{t}^{D}=\alpha^{2}(\alpha+\theta)^{-1}\left(E \Delta e_{t}+k+\delta u r_{t-1}\right)^{2}>0
$$

The approach of this paper, in common with Obstfeld (1997b) and as discussed in the introduction, is to assume that the policymaker must face a political cost if he reneges on a commitment to fix the exchange rate. The decision to devalue then involves a comparison between this political devaluation cost and the net loss from maintaining the fixed exchange rate, given by $L_{t}^{F}-L_{t}^{D} \cdot{ }^{\natural}$ Suppose the political cost of devaluation is $c^{2}$. Using (9) we can determine that the policymaker will only maintain the fixed rate if $c \geq T_{t}$ where:

$$
T_{t}=\alpha(\alpha+\theta)^{-1 / 2}\left(E \Delta e_{t}+k+\delta u r_{t-1}\right)
$$

$T_{t}$ is a measure of the temptation to devalue. Note that because this temptation is increasing in the expected devaluation rate, an expectation of devaluation can make an actual devaluation

\footnotetext{
$7 \quad$ Note that discretionary monetary policy might be superior to a binding commitment if unemployment is subject to a stochastic shock.

$8 \quad$ Drazen and Masson (1994) and Masson (1995) depart from this convention. In their model there is no cost of reneging; instead any incentive to maintain a fixed exchange rate follows from the arbitrary assumption that a devaluation must be of an exogenously fixed size.

Note that the possibility of revaluation is ruled out by assumption.
} 
more likely. It is this circularity creates that results in the potential for multiple equilibria to exist.

For a given level of temptation it is the political cost of devaluation which determines whether the peg will be maintained. In the introduction we argued that a currency board system will tend to impose a relatively high cost of devaluation. This explains why, under normal conditions, a currency board can provide a credible commitment to fix the exchange rate.

To close this model we need to specify the environment within which the public form expectations about the exchange rate, and to solve for the expected exchange rate as a function of the other parameters of the model. It is at this point that the model of this paper diverges significantly from Obstfeld (1997b). In Obstfeld's model there are shocks to unemployment which create uncertainty, and it is this that shapes the expectations of the public. In this present paper there are no shocks to unemployment and instead it is incomplete information about the political cost of devaluation that shapes the expectations of the public. In the following sections we demonstrate how incomplete information can undermine the credibility of a fixed exchange rate and cause cumulative changes in unemployment. If these changes are sufficiently adverse then even a regime which imposes a high devaluation cost on the policymaker can become vulnerable to a speculative attack.

Drazen and Masson (1994) and Masson (1995) also consider the implications of incomplete information and unemployment persistence using a model which is based on an earlier version of Obstfeld's model. However, the analysis of this paper differs from theirs in three important respects. First, the question being addressed is different. Drazen and Masson are interested in whether fixing the exchange rate in one period will raise or lower the credibility of an adjustable exchange rate peg in the subsequent period. Here, we are concerned with whether a cumulative deterioration in fundamentals can result in the collapse of a currency board system under which the policymaker pays a high cost if he devalues. Second, our assumptions are different in some important respects. In the Drazen and Masson papers the incentive to maintain the fixed exchange rate is simply the result of the assumption that any devaluation must be of an arbitrarily fixed size. In this present paper the incentive to maintain the fixed rate comes from the fixed cost that the policymaker must pay if he reneges on this commitment. Our assumption is more conventional, and - we believe - much more realistic - although it does make the model more difficult to solve. However, it also allows us to differentiate between different types of exchange rate commitment which tend to impose different costs on the policymaker if he devalues. In the present model the incomplete 
information concerns the magnitude of this cost. In the Drazen and Masson papers it concerns the relative preference of the policymaker for surprise devaluation over exchange rate stability. Finally, our results differ in a number of respects, but perhaps the most important is that we identify the potential for multiple equilibria to exist. Because multiple equilibria exist the timing of difficulties that a currency board might face is unpredictable.

\section{Incomplete Information}

This section examines the implications of there being incomplete information about the political cost of devaluation. Suppose that in period $t$ the public believe $c$ is drawn from a probability distribution, $c \sim\left[\underline{c}_{t}, \bar{c}\right]$ where $0 \leq \underline{c}_{t}<\bar{c}$. The time subscript on the lower bound indicates that this may change over time as the public learn about the range of possible values the devaluation cost may take from the observed exchange rate decisions of the policymaker. 1 The policymaker knows the true value of $c$, but the public can only form devaluation expectations on the basis of their beliefs about the true value of $c$, which are summarised by this probability distribution.

Suppose that in period $t$ the public expect the policymaker will devalue if $c<c_{t}^{*}$ where $\underline{c}_{t} \leq c_{t}^{*} \leq \bar{c}$. In equilibrium this expectation must be correct. First we derive conditions for the existence of a full credibility equilibrium (FC), in which $c_{t}^{*}=\underline{c}_{t}$, and a zero credibility equilibrium (ZC), in which $c_{t}^{*}=\bar{c}$, before deriving conditions for the existence of partial credibility equilibria (PC), in which $\underline{c}_{t}<c_{t}^{*}<\bar{c}$.

In the FC case the public expect the policymaker will maintain the fixed rate for sure, regardless of the true devaluation cost. A necessary and sufficient condition for the existence of a FC equilibrium is that $\underline{c}_{t}>T_{t}$ when $E \Delta e_{t}=0$. Using (10) this condition becomes:

$$
k+\delta u r_{t-1}<\underline{c}_{t} \alpha^{-1}(\alpha+\theta)^{1 / 2}
$$

\footnotetext{
10 Following a period in which a devaluation occurs the public might also learn about $\bar{c}$. This possibility is ignored as our concern is with the circumstances under which the policymaker might be forced to devalue in the first instance.

${ }_{11}$ In this section Bayesian Nash equilibria are derived in which each player's strategy is optimal given their type, their beliefs, and the equilibrium strategy of the other players. In this context the type of the policymaker is given by the devaluation cost. The strategy of the policymaker specifies an action - in the form of the exchange rate decision - given his type. The strategy of the public specifies an action in the form of a devaluation expectation. The relevant beliefs are the probabilities the public attach to the policymaker being of a particular type, which depend on the probability distribution from which the true value $c$ is drawn.
} 
In the $\mathrm{ZC}$ case the public expect the policymaker to devalue, regardless of the true devaluation cost. A necessary and sufficient condition for the existence of a $\mathrm{ZC}$ equilibrium is that $\bar{c}<T_{t}$ when the expected devaluation is given by equation (5). Using (10) this condition becomes:

$$
\bar{c} \theta \alpha^{-1}(\alpha+\theta)^{-1 / 2}<k+\delta u r_{t-1}
$$

From (11) and (12) we can see that whether or not FC or ZC equilibria exist depends critically on the size of the lower and upper bounds for the devaluation penalty, $\underline{c}_{t}$ and $\bar{c}$, relative to $k$ and $u r_{t-1}$. In particular note that higher unemployment last period will mean it is more likely that a ZC equilibrium will exist, and less likely that a FC equilibrium will exist. We can see by comparison of (11) and (12) that it is possible for both the FC and ZC equilibria to exist at the same time providing:

$$
\theta \bar{c} \alpha^{-1}(\alpha+\theta)^{-1 / 2}<k+\delta u r_{t-1}<\underline{c}_{t} \alpha^{-1}(\alpha+\theta)^{1 / 2}
$$

given

$$
\bar{c}<\underline{c}_{t}(\alpha+\theta) \theta^{-1}
$$

It has already been argued that the key factor that distinguishes a currency board from other forms of exchange rate peg is the size of the political cost of devaluation. It seems reasonable that this should be reflected by the beliefs of the public, and so $\underline{c}_{t}$ and $\bar{c}$ will also tend to be higher. This means that other things being equal (and in particular unemployment see below) it is more likely that a FC equilibrium will exist, and less likely that a $\mathrm{ZC}$ equilibrium will exist, under a currency board as opposed to other forms of exchange rate peg.

Finally, consider the conditions for the existence of a partial credibility equilibrium. In a PC equilibrium the policymaker will devalue if the true devaluation cost is below the threshold $c_{t}^{*}$, where $\underline{c}_{t}<c_{t}^{*}<\bar{c}$. This threshold will itself depend on the expected rate of devaluation. To identify PC equilibria we need to derive a pair of functions: $c_{t}^{*}\left(E \Delta e_{t}\right)$ shows how the threshold changes with the expected rate of devaluation; and $E \Delta e_{t}\left(c_{t}^{*}\right)$ shows how the expected rate of devaluation changes with the threshold, given that the public form expectations rationally.

First, we derive the function $c_{t}^{*}\left(E \Delta e_{t}\right)$. If the true cost of devaluation, $c$, is equal to the threshold, $c_{t}^{*}$, the policymaker will be indifferent between the alternatives of fixing the exchange rate and devaluation. We can use this condition to solve for the threshold, $c_{t}^{*}$. As 
the policymaker will be indifferent between the alternatives of fixing and devaluation if $c=T_{t}$, by substitution in (10):

$$
c_{t}^{*}=\alpha(\alpha+\theta)^{-1 / 2}\left(E \Delta e_{t}+k+\delta u r_{t-1}\right)
$$

Note that this function is linear in the expected devaluation rate, $E \Delta e_{t}$, and that $u r_{t-1}$ acts as a shift term.

Second, we derive the function $E \Delta e_{t}\left(c_{t}^{*}\right)$. Note that we can write this expectation as $E \Delta e_{t}=E\left(\Delta e_{t} \mid\right.$ Devalue $) \cdot \operatorname{Prob}($ Devalue $)$. The probability of devaluation is given by $F_{t}\left(c_{t}^{*}\right)$, where $F_{t}(\cdot)$ is the distribution function for $c$ which summarises the beliefs held by the public in period $t$ about the true value of $c . E\left(\Delta e_{t} \mid\right.$ Devalue) is given by equation (3). After substitution we can solve for $E \Delta e_{t}$ to get:

$$
E \Delta e_{t}\left(c_{t}^{*}\right)=\frac{\alpha F_{t}\left(c_{t}^{*}\right)}{\alpha+\theta-\alpha F_{t}\left(c_{t}^{*}\right)}\left(k+\delta u r_{t-1}\right)
$$

Without specifying a specific form for the distribution function, $F_{t}(\cdot)$, we can determine that (15) has the following properties:

P1. As $E \Delta e_{t}$ is increasing in $F_{t}\left(c_{t}^{*}\right)$, and $F_{t}\left(c_{t}^{*}\right)$ is increasing in $c_{t}^{*}$, it follows that $E \Delta e_{t}$ is increasing in $c_{t}^{*}$.

P2. As $F\left(\underline{c}_{t}\right)=0, E \Delta e_{t}\left(\underline{c}_{t}\right)=0$.

P3. As $F(\bar{c})=1, E \Delta e_{t}(\bar{c})=\alpha \theta^{-1}\left(k+\delta u r_{t-1}\right)$.

Note that this function is likely to be non-linear, and this creates the potential for the existence of multiple PC equilibria. To see why multiple equilibria might exist consider figure 1 below. In parts (a) and (b) of this figure we plot the same function for $c_{t}^{*}\left(E \Delta e_{t}\right)$, given by (14) above. In parts (a) and (b) we also plot two different functions for $E \Delta e_{t}\left(c_{t}^{*}\right)$ which reflect different probability distributions, but both of these functions satisfy properties P1, P2, and $\mathrm{P} 3$ given above. In both parts we can see that no $\mathrm{ZC}$ equilibrium exists, but there is an $\mathrm{FC}$ equilibrium: there is no ZC equilibrium as when $E \Delta e_{t}=(\alpha / \theta)\left(k+\delta u r_{t-1}\right), c_{t}^{*}<\bar{c}$; but there is a FC equilibrium as when $E \Delta e_{t}=0, c_{t}^{*}<\underline{c}_{t}$. Earlier in this section it was argued that this situation is more likely under a currency board than other forms of exchange rate peg, but this is not essential for the purpose of the following discussion in which the focus is on PC

12 The importance of lagged unemployment will be underlined in the next section when we consider dynamic effects. 
equilibria, shown in figure 1 by the interior solutions. In part (a) of the diagram there is no interior solution, but in part (b) there are two equilibrium points of intersection between the functions (only the second of which is stable).

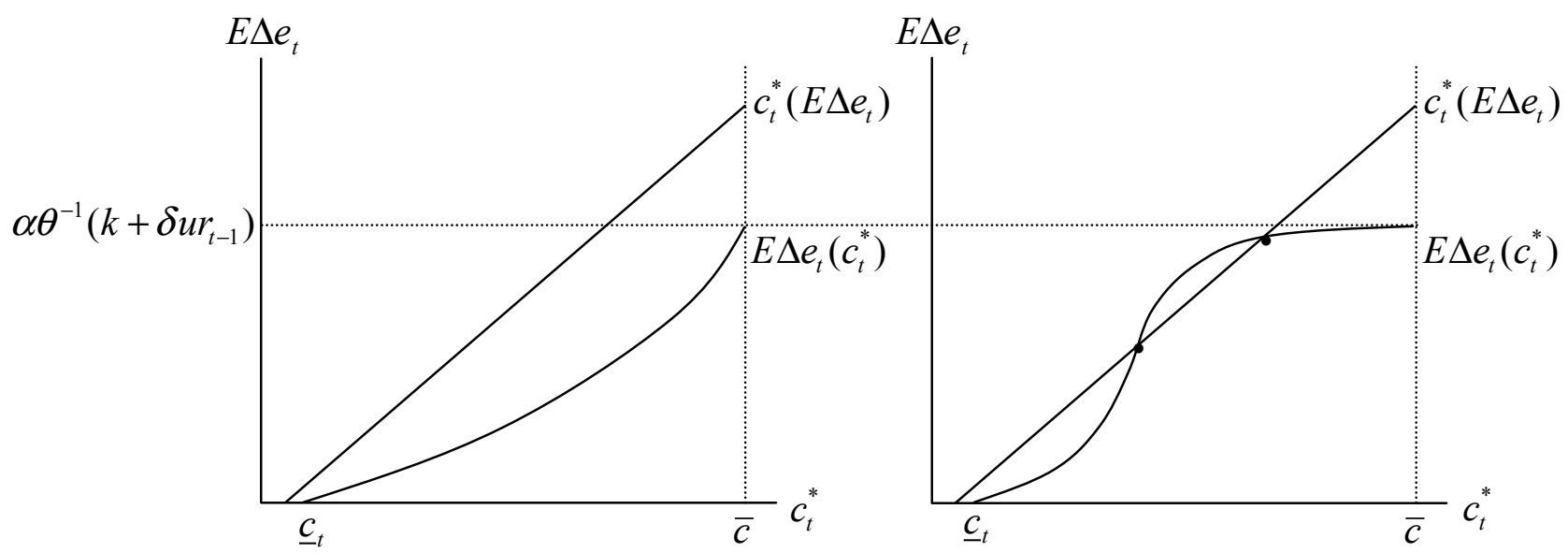

Figure 1(a)

Figure 1(b)

The key factor which determines whether we have multiple equilibria is the distribution function $F_{t}(\cdot)$. In figure 1(a) the function $E \Delta e_{t}\left(c_{t}^{*}\right)$ has been drawn under the assumption that $c$ is drawn from a uniform distribution, whereas in figure 1(b) we assume the density function, $f_{t}(\cdot)=F_{t}^{\prime}(\cdot)$ has a single peak. If the density function has multiple peaks, we may have more than two PC equilibria.

To understand the implications of the analysis of this section, suppose we take the rate of unemployment in period $t-1$ as given. A sufficiently high value of $c$ is necessary and sufficient to ensure that the currency board is maintained in period $t$. However, whilst this is necessary, it is not sufficient, to ensure that the currency board can be maintained at a low cost. If the beliefs of the public are such that they attach sufficient weight to the possibility that the true value of $c$ takes on a lower value, multiple equilibria can exist, with the possibility that the outcome is a PC equilibrium in which the currency board can only be maintained at a high cost in terms of unemployment. Given the constraints imposed on the policymaker by a currency board there is no means by which he can act to drive down unemployment. If unemployment is persistent, this can create additional problems for the policymaker, as it can increase the pressure to devalue in subsequent periods. Is it possible that it may do so to such an extent over time that the policymaker is eventually forced to 
abandon a currency board even if the true devaluation cost is very high? This is the question to which we turn in the following section.

\section{Inter-temporal Linkages and Dynamic Effects}

In this section we consider the implications of the outcome in one period for the equilibria that exist in subsequent periods, given the inter-temporal linkages that are present in this model. In particular we are interested in the following question: can fundamentals, in the form of unemployment, deteriorate over time to such an extent that a currency board, which imposes a high devaluation cost upon the policymaker, becomes vulnerable to collapse? There are two inter-temporal linkages present in this model: first, unemployment is persistent, as can be seen from equation (2); and second, the exchange rate outcome in one period may be informative about the policymaker type, and can therefore affect the beliefs of the public and their devaluation expectations in subsequent periods. We consider the implications of each of these inter-temporal linkages in turn.

Suppose that unemployment is equal to its steady-state value. This is the rate to which the unemployment rate will converge in the absence of exchange rate surprises. From (2), given $E \Delta e_{t}=\Delta e_{t}, u r_{t}=\alpha^{1 / 2}\left[k+\delta u r_{t-1}\right]$. Setting $u r_{t}=u r_{t-1}=\overline{u r}$, and solving for this, the steady state value, we get:

$$
\overline{u r}=\alpha^{1 / 2} k\left(1-\delta \alpha^{1 / 2}\right)^{-1}
$$

Now suppose the policymaker fixes the exchange rate in period $t$. This will be the outcome in either the FC case, or in the PC case if the true devaluation cost is sufficiently high $\left(c>c_{t}^{*}\right)$. In the FC case the expected devaluation is zero; this means that unemployment will remain unchanged at its steady-state value. By contrast, in the PC case the expected devaluation rate is positive. If the policymaker maintains the fixed rate this means that the deviation of unemployment from the target rate will rise, and because unemployment deviations are persistent this will cause unemployment to rise in subsequent periods by an amount that depends on the autoregressive coefficient, $\alpha^{1 / 2} \delta$ (this coefficient can be derived

13 Recent experience in Argentina suggests the multiple equilibrium feature of the model is realistic. For a short period in early 1995, following the forced devaluation of the Mexican peso, the Argentinean currency board came under considerable pressure. The behaviour of interest rates at this time indicates a sharp increase in the expected rate of devaluation (see Berg and Borensztein, 2000). However, the pressure to devalue was resisted and the expectation of devaluation soon subsided. The longer-term consequence was a rise in unemployment that persisted for a number of years. This behaviour is consistent with the existence of two (stable) equilibria in both 
from equation 2). It is possible, therefore, that fixing the exchange rate in period $t$ can raise unemployment in both period $t$ and in subsequent periods.

The second inter-temporal linkage results from the effect that the outcome in one period has on the beliefs of the public in subsequent periods. This is because the outcome in one period may be informative about the policymaker type. To see this, suppose that in period $t$ the equilibrium is PC, but the policymaker does not devalue. In a PC equilibrium this can only occur if the true devaluation cost exceeds $c_{t}^{*}$. In period $t+1$ therefore, the public will know that $c$ must lie within the range $\left.\left[c_{t}^{*}, c\right] \cdot\right]^{4}$ Other things being equal, this will reduce the expected rate of devaluation in the second period. Note that learning of this sort does not occur if the equilibrium is $\mathrm{FC}$ (or ZC), because the policymaker action is the same regardless of the true value of the devaluation cost, and so no inference can be made about this devaluation cost when the action is observed.

When we consider the combined effect of these inter-temporal linkages we can see that, if the policymaker fixes the exchange rate in period $t$, the impact on the outcome in period $t+1$ will depend on whether the equilibrium is FC or PC in period $t$. If the equilibrium is FC there is no effect: unemployment remains unchanged at the steady state value, and the public do not learn about the true devaluation cost. But in the PC case there are two competing effects: on the one hand a positive devaluation expectation in period $t$ will raise unemployment in that period, and because unemployment deviations are persistent, this will also raise unemployment in period $t+1$; but on the other, if the policymaker does not devalue in period $t$, this will demonstrate to the public that the true devaluation cost must exceed $c_{t}^{*}$, and this will tend to make the promise to maintain the fixed rate in subsequent periods more credible. The implications of both effects can be understood using figure 2 below.

In figure 2 we can see that in period $t$ there are multiple equilibria, as in figure $1 \mathrm{~b}$ above. Suppose that the outcome in period $t$ is the stable PC equilibrium shown by point $A$ in figure 2. In this equilibrium a devaluation is expected, but if the true devaluation cost exceeds the threshold, $c_{t}^{*}$, no devaluation occurs, and so unemployment rises. At the same time, because there is no devaluation, the public learn that the true devaluation cost must exceed $c_{t}^{*}$, and so $\underline{c}_{t+1}=c_{t}^{*}$. From the diagram we can see how these effects impact on the functions $c_{t+1}^{*}\left(E \Delta e_{t+1}\right)$ and $E \Delta e_{t+1}\left(c_{t+1}^{*}\right)$. The implication for the function $c_{t+1}^{*}\left(E \Delta e_{t+1}\right)$ is straightforward. 
From equation (14) we can see that higher unemployment in period $t$ will shift this function down in the manner indicated by the arrow: higher unemployment in period $t$ means that the trigger value in $t+1$, for a given devaluation expectation, will increase. The implications for the function $E \Delta e_{t+1}\left(c_{t+1}^{*}\right)$ are more complicated and to understand these we break the problem down into three parts. First, because $\underline{c}_{t+1}>\underline{c}_{t}$, as a result of learning by the public, the starting point of this function moves to point $B$. Second, from equation (5), higher unemployment means the end point of the function moves from $A^{\prime}$ to $B^{\prime}$. Finally, the shape of the function between points $B$ and $B^{\prime}$ will depend on the probability distribution for $c$ between the new lower bound, $\underline{c}_{t+1}$, and the upper bound, $\bar{c}$, and this will reflect the shape of the original function along the segment $A A^{\prime}$.

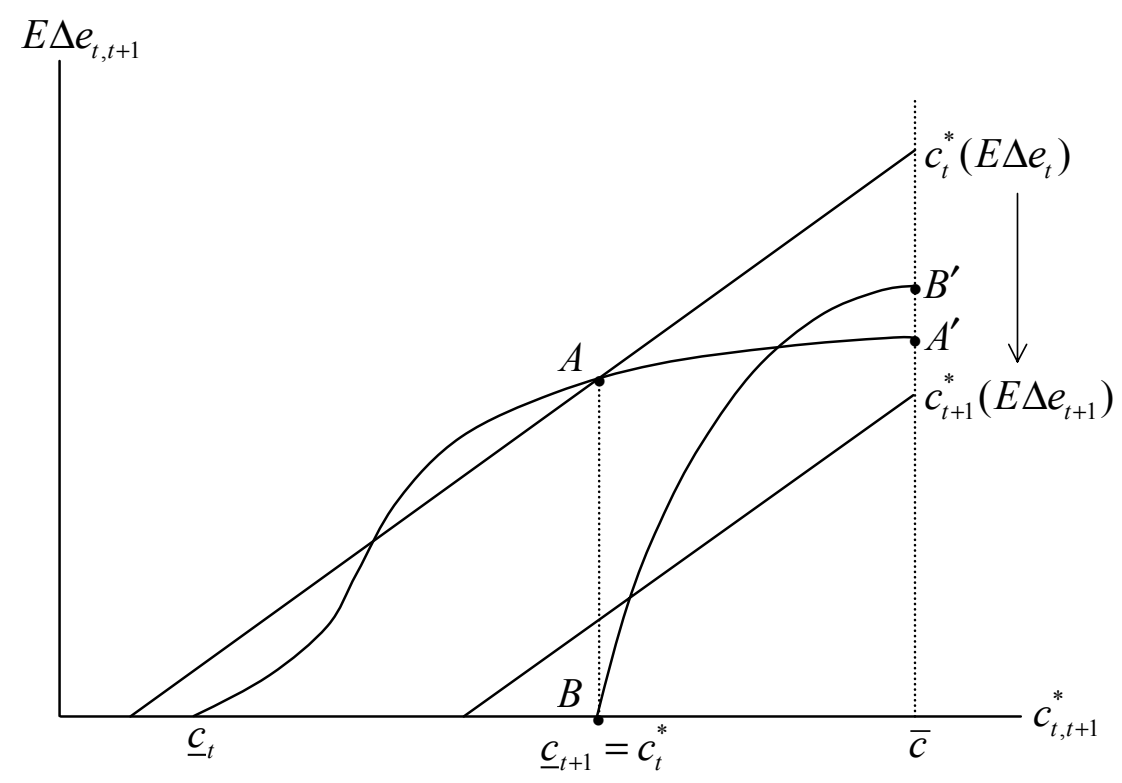

Figure 2

As figure 2 has been drawn there will still be multiple equilibria in period $t+1$. There is an $\mathrm{FC}$ equilibrium (point $B$ ) and a $\mathrm{ZC}$ equilibrium (point $B^{\prime}$ ), plus an unstable $\mathrm{PC}$ equilibrium (shown by the point of intersection between the functions). There is no longer a stable PC equilibrium. This is so because now the $c_{t+1}^{*}\left(E \Delta e_{t+1}\right)$ and $E \Delta e_{t+1}\left(c_{t+1}^{*}\right)$ functions intersect just once. However, this need not be the case. Indeed, if the unemployment effect had been less strong compared to the learning effect, we might have a stable PC equilibrium in period $t+1$ such that $c_{t+1}^{*}>c_{t}^{*}$, but no ZC equilibrium. If the learning effect were stronger

$14 \quad$ Formally, we are assuming Bayesian learning occurs.

15 This would be the case if there were two points of intersection between $c_{t+1}^{*}\left(E \Delta e_{t+1}\right)$ and the curve $B B^{\prime}$. 
still, compared to the unemployment effect, the unique equilibrium in period $t+1$ might be a FC equilibrium.

An important question, therefore, is whether the learning effect or the unemployment effect dominates, and, as a result, what will be the implications for the equilibria that exist in subsequent periods? Will PC equilibria exist in period $t+1$ such that $c_{t+1}^{*}>c_{t}^{*}$ ? Will a ZC equilibrium exist in period $t+1$, even though no ZC equilibrium exists in period $t$ ?

There are no general answers to these questions, as the outcome in period $t+1$ will depend on the underlying probability distribution from which $c$ is drawn and the other parameters of the model. However, in the following subsections we substantiate two claims. First, if $c_{t}^{*}$ is sufficiently high relative to $\bar{c}$ then a ZC equilibrium will exist in period $t+1$ (as in figure 2), irrespective of the probability distribution from which $c$ is drawn. This means that even if the policymaker fixes the exchange rate in period $t$, he might be forced to devalue in period $t+1$. Second, if there is no upper bound to the distribution from which $c$ is drawn, it is feasible that a succession of PC equilibria might be realised such that $c_{t}^{*}$ and $u r_{t}$ are everincreasing, so that the fixed exchange rate can eventually become vulnerable to collapse no matter how high the true value of $c$ is. This second claim implies that in these circumstances there is no such thing as a binding exchange rate commitment.

\subsection{From PC to ZC}

This subsection demonstrates how a PC equilibrium in period $t$ can lead to a ZC equilibrium in period $t+1$. Note that the condition for the existence of a ZC equilibrium, given by equation (12), depends on $u r_{t-1}, \bar{c}$, and other parameters of the model. Importantly, it does not depend on $\underline{c}_{t}$. As we have discussed, if we have a $P C$ equilibrium in period $t$, but the policymaker does not devalue, the public learn about the policymaker type so that $\underline{c}_{t+1}=c_{t}^{*}>\underline{c}_{t}$, and because $E \Delta e_{t}>\Delta e_{t}$ unemployment will rise so that $u r_{t}>\overline{u r}$. But only the second effect has any bearing on the condition for a ZC equilibrium in period $t+1$. We can therefore reach the following unambiguous conclusion: if the equilibrium is $\mathrm{PC}$ in period $t$ and the policymaker maintains the fixed exchange rate, the condition for the existence of a $\mathrm{ZC}$ equilibrium in period $t+1$ is weaker than in period $t$. In a ZC equilibrium the policymaker is

16 This would be the case if $c_{t+1}^{*}\left(E \Delta e_{t+1}\right)$ was everywhere above, and so did not intersect with, $B B^{\prime}$. 
forced to devalue even if the true cost of devaluation is large, and so even a (relatively) high commitment regime is vulnerable to collapse.

From (2), if the policymaker maintains the fixed exchange rate in period $t$, the unemployment rate is given by:

$$
u r_{t}=\alpha^{1 / 2}\left[E \Delta e_{t}+k+\delta \overline{u r}\right]=\overline{u r}+\alpha^{1 / 2} E \Delta e_{t}
$$

Clearly $u r_{t}>\overline{u r}$ when $E \Delta e_{t}>0$. In a PC equilibrium the expected devaluation is given by (15). Using (15) and (16):

$$
k+\delta u r_{t}=(k+\delta \overline{u r})\left[1+\frac{\delta \alpha^{3 / 2} F_{t}\left(c_{t}^{*}\right)}{\theta+\alpha\left(1-F_{t}\left(c_{t}^{*}\right)\right)}\right]
$$

In period $t+1$ the condition for a $Z C$ equilibrium is the same as (12). But following a PC equilibrium this condition is necessarily weaker, by a factor equal to the term in square brackets in equation (17). This term is increasing in $\alpha$ and in $c_{t}^{*}$, although the precise relationship with $c_{t}^{*}$ will depend on the distribution function, $F_{t}\left(c_{t}^{*}\right)$, which reflects the prior beliefs held by the public. On the other hand this term is decreasing in $\theta$, which reflects the relative importance of exchange rate stability in the policymaker loss function. Condition (17) also show the importance of $\delta$, which is the unemployment persistence parameter. The more persistent unemployment is, the more likely it is that a $\mathrm{ZC}$ equilibrium will exist in period $t+1$, and so a high degree of unemployment persistence can present a threat to the sustainability of a currency board.

\subsection{Ever-Increasing $P C$}

This subsection demonstrates how, under certain conditions, the realisation of a succession of PC equilibria can raise the unemployment rate to such an extent that the policymaker will be forced to renege on the fixed exchange rate commitment, no matter how high the true devaluation cost is. The specific question addressed is whether the realisation of a stable PC equilibrium in one period will result in the existence of a stable PC equilibrium in the following period. If this is true over a number of periods this implies that $c_{t}^{*}$ can rise over time; if this is true indefinitely, this implies that $c_{t}^{*}$ can also rise indefinitely. This in turn implies that the policymaker will eventually devalue when $c_{t}^{*}$ rises above the true devaluation cost, $c$. 
Suppose the public believe the true cost of devaluation is drawn from a Pareto distribution so that $F_{t+1}(c)=1-\left(\underline{c}_{t+1} / c\right)^{2}$, for $c \geq \underline{c}_{t+1} \cdot 17$ Assume there is a PC equilibrium in period $t$, but the policymaker does not devalue. Bayesian learning implies that $\underline{c}_{t+1}=c_{t}^{*}$ and so $F_{t+1}\left(c_{t+1}^{*}\right)=1-\left(c_{t}^{*} / c_{t+1}^{*}\right)^{2}$. Note that the Pareto distribution has no upper bound.

By substitution into (15) we can determine the expected rate of devaluation in a PC equilibrium, given this distribution:

$$
E \Delta e_{t+1}\left(c_{t+1}^{*}\right)=\frac{\alpha\left(c_{t+1}^{*}\right)^{2}-\alpha\left(c_{t}^{*}\right)^{2}}{\theta\left(c_{t+1}^{*}\right)^{2}+\alpha\left(c_{t}^{*}\right)^{2}}\left(k+\delta u r_{t}\right)
$$

We can then substitute this into (14) and solve for $c_{t+1}^{*}$. We disregard the negative root, as this corresponds to the unstable equilibrium, and instead we focus on the positive root which corresponds to the stable equilibrium:

$$
c_{t+1}^{*}=(\alpha / 2 \theta)\left[(\alpha+\theta)^{1 / 2}\left(k+\delta u r_{t}\right)+\left((\alpha+\theta)\left(k+\delta u r_{t}\right)^{2}-4 \theta \alpha^{-1}\left(c_{t}^{*}\right)^{2}\right)^{1 / 2}\right]
$$

This expression can be simplified by noting that unemployment, $u r_{t}$, is itself a function of $c_{t}^{*}$. In the appendix it is shown that, if there is a PC equilibrium in period $t$, but there is no devaluation, the unemployment rate is:

$$
u r_{t}=\alpha^{-1 / 2}(\alpha+\theta)^{1 / 2} c_{t}^{*}
$$

Substituting (20) into (19) we can re-write the equation for $c_{t+1}^{*}$ :

$$
\begin{aligned}
c_{t+1}^{*} & =(\alpha / 2 \theta)(\alpha+\theta)^{1 / 2}\left(k+((\alpha+\theta) / \alpha)^{1 / 2} \delta c_{t}^{*}\right) \\
& +(\alpha / 2 \theta) \sqrt{(\alpha+\theta)\left(k+((\alpha+\theta) / \alpha)^{1 / 2} \delta c_{t}^{*}\right)^{2}-4(\theta / \alpha)\left(c_{t}^{*}\right)^{2}}
\end{aligned}
$$

The question to be resolved is whether a PC equilibrium, with $c_{t+1}^{*}$ given by (21), actually exists in period $t+1$. There are two conditions that together are necessary and sufficient for the existence of a stable PC equilibrium in period $t+1$. First, the term under the square root sign must be positive. Second, we must have $c_{t+1}^{*}>c_{t}^{*}$, as this is the lower bound for the distribution function, $F_{t+1}(\cdot)$.

Proposition 1: if we assume $\alpha>\theta$ a necessary and sufficient condition for the existence of a PC equilibrium in period $t+1$ is:

$$
c_{t}^{*}\left[2 \theta^{1 / 2}-\delta(\alpha+\theta)\right] \leq \alpha^{1 / 2}(\alpha+\theta)^{1 / 2} k
$$

A proof is given in the appendix.

17 This distribution has been chosen so that an analytic solution of the model can be derived, and not 
Suppose this condition is satisfied. If the outcome is the PC equilibrium in period $t$, and the policymaker maintains the fixed exchange rate, a PC equilibrium will exist in period $t+1$ such that $c_{t+1}^{*}>c_{t}^{*}$. Furthermore, if the term in square brackets in (22) is negative, this condition holds irrespective of how high $c_{t}^{*}$ is. This will be the case if:

$$
\delta>2 \theta^{1 / 2}(\alpha+\theta)^{-1}
$$

If the persistence parameter, $\delta$, is sufficiently high, so that (23) is satisfied, it is at least possible that a succession of PC equilibria could force the policymaker to quit the fixed exchange rate, no matter how high the true devaluation cost is. ${ }^{18}$ This is because unemployment can rise to such an extent over time, that this necessarily outweighs any signalling effect associated with the public learning about the true devaluation cost, following a succession of PC equilibria in which the policymaker maintains the fixed exchange rate.

\section{Conclusions}

This paper has shown how a currency board can become vulnerable to speculative attack, in a model with incomplete information about the political cost the policymaker faces upon devaluation, and with persistence in unemployment. The problem for the policymaker is that incomplete information about the cost of devaluation can create an expectation of devaluation, which, if it is not realised, causes unemployment. If unemployment is persistent, this can result in a build-up of pressure on the policymaker which sustains the expectation of devaluation in subsequent periods. If unemployment rises sufficiently over time, then the expectation of devaluation might become self-fulfilling, so the that the policymaker is forced to abandon the exchange rate peg, even if the true cost of devaluation is high.

In this model multiple equilibria may exist, and so the precise outcome cannot be predetermined. It is not possible to identify how an when the switch from one equilibrium to another might occur. The implication of this is that a currency board can perform well for a period of time. This is the case in the $\mathrm{FC}$ equilibrium in which there is no expectation of devaluation. However, if other equilibria exist, the currency board can come under sudden pressure. And this could set in progress a chain of events, described above, which leads to the collapse of a currency board.

because it is more plausible than any other prior probability distribution.

18 Condition (23) is also sufficient to rule out the asymptotic convergence of $c_{t}^{*}$ on a finite value. This is apparent from the proof of proposition 1 given in the appendix. 
The welfare consequences of the collapse of a currency board are necessarily severe. Because the cost of devaluation faced by the policymaker is relatively high, the circumstances under which devaluation occurs must be sufficiently adverse. Furthermore, this is the result of a sustained and gradual deterioration of fundamentals if the policymaker is only willing to quit, and pay the political cost from doing so, after a number of periods of bad economic outcomes. This means that a high cost, in social welfare terms, must be borne for a number of periods before the system collapses.

The main conclusion that should be drawn is as follows. Even if a currency board system imposes a high cost on the policymaker upon the occurrence of a devaluation, this may not in itself be sufficient to prevent a devaluation occurring at some stage in the future. To deter any devaluation in the future two conditions must be satisfied: first, the cost of devaluation faced by future policymakers must also be high; and second, the incomplete information about this cost must be minimised, so as to prevent a credibility problem from growing into a crisis. This latter problem has been the focus of this analysis, but the two problems are clearly related. As was emphasized in the introduction, it is not clear how these problems can be overcome.

This analysis underlines the need for caution by countries contemplating the adoption of currency board systems as a means to achieve monetary stabilisation. It suggests that the 'two-corner solution' approach to exchange rate policy may be flawed, because one of these corners - a supposedly irrevocable commitment in the form of a currency board - might not provide immunity from currency crises. Whether the remaining corner - a floating exchange rate - is superior to the middle ground, involving exchange rate intervention of some degree, is another question.

\section{Appendix 1: Derivation of Unemployment Equation (20)}

As there is a PC equilibrium in period $t$ we can lag (18) by one period and substitute this into equation (2):

$$
u r_{t}=\alpha^{1 / 2}\left[\frac{(\alpha+\theta)\left(c_{t}^{*}\right)^{2}}{\theta\left(c_{t}^{*}\right)^{2}+\alpha\left(c_{t-1}^{*}\right)^{2}}\right]\left(k+\delta u r_{t-1}\right)
$$

This expression can be simplified by using (19). After lagging by one period, we can rearrange (19) to get $2 \theta \alpha^{-1} c_{t}^{*}-(\alpha+\theta)^{1 / 2}\left(k+\delta u r_{t-1}\right)=\left((\alpha+\theta)\left(k+\delta u r_{t-1}\right)^{2}-4 \theta \alpha^{-1}\left(c_{t-1}^{*}\right)^{2}\right)^{1 / 2}$. Squaring both sides this simplifies to $\theta\left(c_{t}^{*}\right)^{2}+\alpha\left(c_{t-1}^{*}\right)^{2}=\alpha(\alpha+\theta)^{1 / 2}\left(k+\delta u r_{t-1}\right) c_{t}^{*}$. This 
expression can then be substituted into the equation for unemployment above to yield (20).

\section{Appendix 2: Proof of Proposition 1}

The first necessary condition is that the term under the square root sign of (23) is positive. This requires $(\alpha+\theta)^{1 / 2}\left(k+((\alpha+\theta) / \alpha)^{1 / 2} \delta c_{t}^{*}\right) \geq 2(\theta / \alpha)^{1 / 2} c_{t}^{*}$, which can be re-arranged to give condition (22).

The second necessary condition is that $c_{t+1}^{*}>c_{t}^{*}$. This requires:

$$
\begin{aligned}
& (\alpha / 2 \theta) \sqrt{(\alpha+\theta)\left(k+((\alpha+\theta) / \alpha)^{1 / 2} \delta c_{t}^{*}\right)^{2}-4(\theta / \alpha)\left(c_{t}^{*}\right)^{2}} \\
& >c_{t}^{*}-(\alpha / 2 \theta)(\alpha+\theta)^{1 / 2}\left(k+((\alpha+\theta) / \alpha)^{1 / 2} \delta c_{t}^{*}\right)
\end{aligned}
$$

A sufficient condition is that the right hand side is negative, which is true if:

$$
c_{t}^{*}\left[2 \theta \alpha^{1 / 2}-\delta(\alpha+\theta)\right]<\alpha^{1 / 2}(\alpha+\theta)^{1 / 2} k
$$

Given the assumption that $\alpha>\theta$ this condition is weaker than (22). It follows that condition

(22) is a necessary and sufficient condition for the existence of an equilibrium in period $t+1$.

\section{References}

Baliño, Tomás J.T., Charles Enoch, and other (1997), 'Currency Board Arrangements: Issues and Experiences', IMF Occasional Paper, Washington, August, 151.

Barro, R.J. and D.B. Gordon (1983), 'A Positive Theory of Monetary Policy in a Natural Rate Model', Journal of Political Economy, 91, pp. 589-610.

Berg, A. and E. Borensztein (2000), 'The Pros and Cons of Full Dollarization', IMF Working Paper, Washington, March, WP/00/50.

Collins, Susan M. (1996), 'On Becoming More Flexible: Exchange Rate Regimes in Latin America and the Caribbean', Journal of Development Economics, 51, 117-138.

De Gregorio, José, Barry Eichengreen, Takatoshi Ito, and Charles Wyplosz (1999), 'An Independent and Accountable IMF', Geneva Reports on the World Economy, 1, International Centre for Monetary and Banking Studies, Geneva, and the Centre for Economic Policy Research, London.

Drazen, Allen and Paul Masson (1994), 'Credibility of Policies Versus Credibility of Policymakers', Quarterly Journal of Economics, August. 
Eichengreen, Barry, Paul Masson, Miguel Savastano, and Sunil Sharma (1999), 'Transition Strategies and Nominal Anchors on the Road to Greater Exchange-Rate Flexibility, Essays in International Finance, Princeton University, April, 213.

Enoch, Charles and Anne-Marie Gulde (1997), 'Making a Currency Board Operational', IMF Paper on Policy Analysis and Assessment, Washington, November, 97/10.

Ghosh, Atish R., Anne-Marie Gulde, and Holger C. Wolf (2000), 'Currency Boards: More than a Quick Fix?', Economic Policy, 31, October.

International Financial Institution Advisory Commission (2000), Report of the International Financial Institution Advisory Commission.

International Monetary Fund Staff (1997), World Economic Outlook, International Monetary Fund, Washington, October.

Layard, Richard, Stephen Nickell and Richard Jackman (1991), Unemployment: Macroeconomic Performance and the Labour Market, Oxford University Press

Masson, Paul (1995), 'Gaining and Losing ERM Credibility: The Case of the United Kingdom', Economic Journal, May, 105.

Mussa, Michael, Paul Masson, Alexander Swoboda, Esteban Jadresic, Paolo Mauro, and Andrew Berg (2000), 'Exchange Rate Regimes in an Increasingly Integrated World Economy, IMF Occasional Paper, Washington, 193.

Obstfeld, Maurice (1997a), 'Models of Currency Crises with Self-Fulfilling Features', National Bureau of Economic Research Working Paper, October, 5285.

Obstfeld, Manurice (1997b), 'Destabilizing Effects of Exchange-Rate Escape Clauses', Journal of International Economics, 43.

Rivera Batiz, Luis A. and Amadou N.R. Sy (2000), 'Currency Boards, Credibility, and Macroeconomic Behaviour', IMF Working Paper, Washington, WP/00/97, June.

Williamson, J. (2000), 'Exchange Rate Regimes for Emerging Markets: Reviving the Intermediate Option', Policy Analyses in International Economics, Institute for International Economics, 60. 